Bull. Mater. Sci., Vol. 21, No. 3, June 1998, pp. 185-187. (C) Indian Academy of Sciences.

\title{
Preparation of aluminosilicate precursor by mechanochemical method from gibbsite-fumed silica mixtures
}

\author{
J TEMUUJIN*, T S JADAMBAA ${ }^{\dagger}, K_{\text {OKADA }}^{\dagger \dagger}$ and K J D MACKENZIE ${ }^{\dagger \dagger}$ \\ Institute of Chemistry and Chemical Technology, Mongolian Academy of Sciences, Ulaanbaatar 51, Mongolia \\ 'Department of Chemical Technology, Mongolian Technical University, Ulaanbaatar 46, Mongolia \\ ${ }^{\dagger \dagger}$ Department of Inorganic Materials, Tokyo Institute of Technology, 2-12-1 O-okayama, Meguro-ku, \\ Tokyo 152, Japan \\ ${ }^{\dagger \dagger}$ New Zealand Institute for Industrial Research and Development, P.O. Box 31-310, Lower Hutt, New Zealand
}

MS received 28 January 1998

\begin{abstract}
Aluminosilicate (mullite) precursor was prepared by mechanochemical treatment of gibbsite and fumed silica mixtures. The effect of grinding on its structure and thermal behaviour was examined by ${ }^{27} \mathrm{Al}$ and ${ }^{29} \mathrm{Si}$ MAS NMR, XRD, DTA-TG and FTIR. Thermal treatment of this precursor led to the crystallization of mullite at about $1200^{\circ} \mathrm{C}$ via a spinel-phase. ${ }^{27} \mathrm{AI}$ and ${ }^{29} \mathrm{Si}$ MAS NMR spectroscopies show lowering of mullitization temperature, which is associated with increased homogeneity of the precursor. Mechanochemical treatment of gibbsite and fumed silica mixtures resulted in the formation of a more homogeneous aluminosilicate precursor.
\end{abstract}

Keywords. Mullite; mechanochemistry; NMR.

\section{Introduction}

The homogeneity of aluminosilicate (mullite) precursors depends largely on the processing method, i.e. how to mix, precipitate, hydrolyse or react $\mathrm{SiO}_{2}$ and $\mathrm{Al}_{2} \mathrm{O}_{3}$ components (Schneider et al 1994). As part of work to evaluate the mechanochemical effect for the preparation of aluminosilicate precursors, various alumina-silica mixtures have been milled in a planetary pot mill (Temuujin et al 1997a-d). The homogeneity of these mixtures depends on water and hydroxyl content of the starting materials (Temuujin et al $1997 \mathrm{~b}, \mathrm{c}$ ) and it was noted that the hydroxyls must be associated with the alumina starting material but not necessarily with the initial silica.

Silica gel, fused silica and silicic acid were used as silica source, and found that the homogeneity of resulting precursors depended on the siliceous starting materials. In the present work, aluminosilicate (mullite) precursor was synthesized by mechanochemical activation of gibbsite and fumed silica mixtures and the product compared with those previously obtained under identical conditions using silica gel, fused silica and silicic acid (Temuujin et al 1997b,d).

\section{Experimental}

The starting materials used in the investigation were

*Author for correspondence gibbsite (Showa Denko Co. Ltd., Japan) and fumed silica (Aerosil 200, Aerosil Co. Ltd). The composition of the mixture was $75 \pm 1 \mathrm{wt} \%$ alumina/ $25 \pm 1 \mathrm{wt} \%$ silica, ground for $20 \mathrm{~h}$ in a planetary pot mill (La-PO.1, ITOH Co. Ltd) at room temperature. The rotation speed of planetary pot mill was $400 \mathrm{rpm}$ and milling media and pot were made from silicon nitride. The weight ratio of milling media to powder was $20: 1$.

After grinding, samples were characterized by XRD (RIGAKU, Geigerflex with monochromatized $\mathrm{CuK} \alpha$ radiation), FTIR (SHIMADZU, FTIR 8200 PC with the samples suspended in $\mathrm{KBr}$ discs) and DTA-TG (RIGAKU, Thermoplus TG 8120). ${ }^{29} \mathrm{Si}$ and ${ }^{27} \mathrm{Al}$ MASNMR spectra were obtained at $11.7 \mathrm{~T}$ using a Varian Unity 500 spectrometer and Doty probe spun at 10 $12 \mathrm{kHz}$. The ${ }^{29} \mathrm{Si}$ spectra were acquired using a $90^{\circ}$ pulse of $6 \mu \mathrm{s}$ and recycle time of $100 \mathrm{~s}$, and were referenced to tetramethylsilane (TMS). The ${ }^{27} \mathrm{Al}$ spectra were acquired using a $15^{\circ}$ pulse of $1 \mu \mathrm{s}$ and a recycle time of $1 \mathrm{~s}$ and were referenced to $\mathrm{Al}\left(\mathrm{H}_{2} \mathrm{O}\right)_{6}^{3+}$.

\section{Results and discussion}

The DTA-TG measurements (not shown here), indicate that the intensity of the endothermic effect at $260^{\circ} \mathrm{C}$ due to dehydration of gibbsite decreases with grinding but does not disappear. A new exothermic peak which appears at about $960^{\circ} \mathrm{C}$ is related to the homogeneity of the resulting precursor, as previously described by 


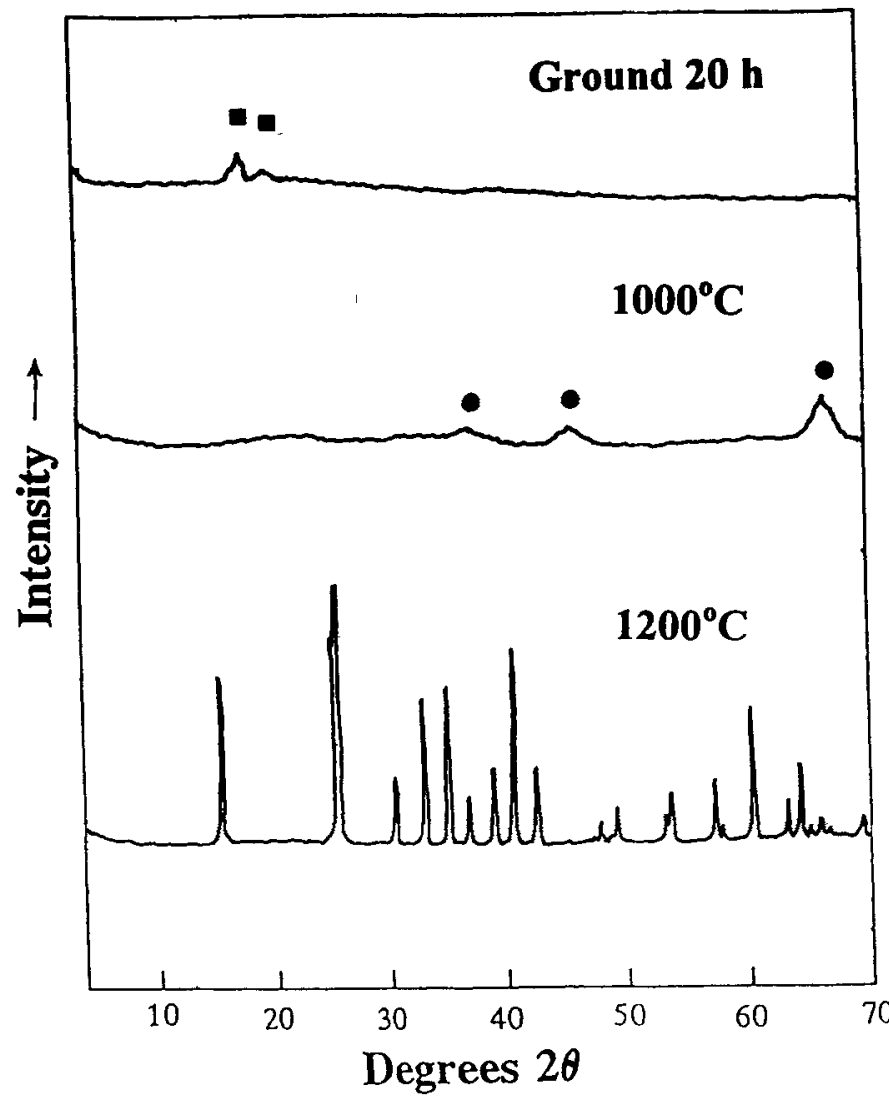

Figure 1. XRD pattern of ground mixtures and after calcining at different temperatures $(\boldsymbol{\square}$, gibbsite; $\bullet$, spinel phase; unmarked peaks, mullite).
Temuujin et al (1997a,b). Figure 1 shows XRD patterns of the mixtures ground for $20 \mathrm{~h}$ and calcined at different temperatures. In contrast with silica gel and silicic acid, the XRD intensities of the gibbsite reflections decrease with grinding and almost disappear. In the $\mathrm{X}$-ray powder diffraction patterns of the samples, calcined for $2 \mathrm{~h}$ at $1000^{\circ} \mathrm{C}$, broad reflections of $\gamma-\mathrm{Al}_{2} \mathrm{O}_{3}$ or spinel-phase are observed. In our previous experiments we have shown that the DTA exothermic effect at about $980^{\circ} \mathrm{C}$ is related to the formation of spinel-phase into which is incorporated a small amount of silica from the aluminosilicate precursor (Temuujin et al 1997c). In the present precursor, mullite crystallizes at $1200^{\circ} \mathrm{C}$ without any other minor phases and its XRD intensity increases with subsequent heat treatments. The thermal behaviour of this precursor can be correlated with the structural changes introduced by grinding.

Grinding for $20 \mathrm{~h}$ causes several $\mathrm{OH}$ stretching vibrations at $3500 \mathrm{~cm}^{-1}$ to merge into a single broad band and $\mathrm{OH}$ bending vibrations around $1020 \mathrm{~cm}^{-1}$ to disappear. Also the absorption band at $1100 \mathrm{~cm}^{-1}$ due to the tetrahedral $\mathrm{Si}-\mathrm{O}$ vibration shifts to $1020 \mathrm{~cm}^{-1}$. This shift to lower wave number can be explained by incorporation of $\mathrm{Al}^{3+}$ into the $\mathrm{Si}^{4+}$ sites (Temuujin et al 1997a,b; Okada and Otsuka 1986). The absorption band at $800 \mathrm{~cm}^{-1}$, arising from three-dimensionally bonded $\mathrm{SiO}_{4}$ (Liao and Senna 1993), also disappears on grinding.

Figure 2 shows the ${ }^{27} \mathrm{Al}$ and ${ }^{29} \mathrm{Si}$ MAS NMR spectra of gibbsite, fumed silica and the ground mixture.

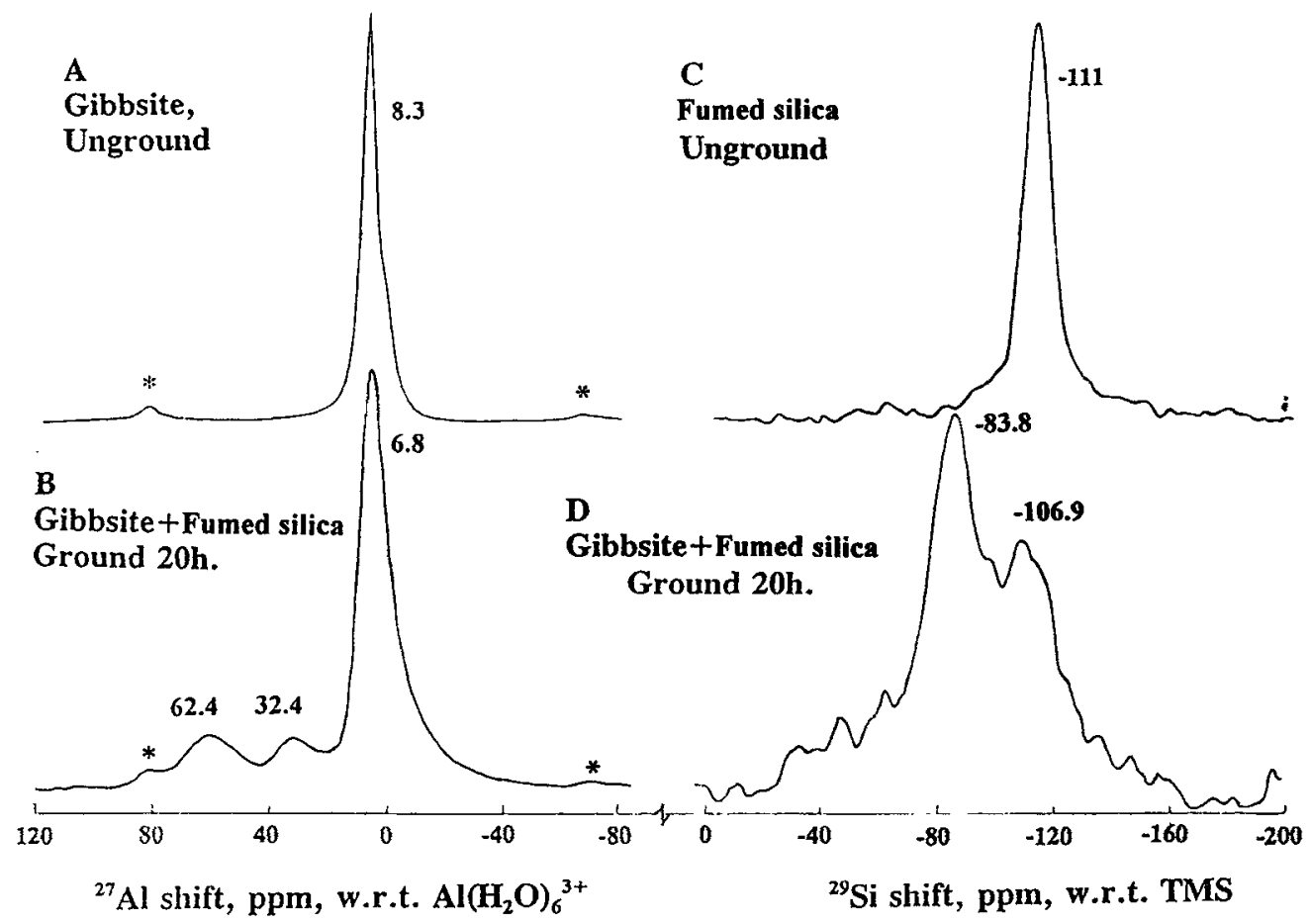

Figure 2. $11.7 \mathrm{~T}^{29} \mathrm{Si}$ and ${ }^{27} \mathrm{Al}$ MAS-NMR spectra of starting materials and ground samples. Asterisks denote spinning side bands. 
Unground gibbsite shows the octahedral ${ }^{27} \mathrm{Al}$ resonance at $8.3 \mathrm{ppm}$, and unground fumed silica shows ${ }^{29} \mathrm{Si}$ resonance in the $\mathrm{SiO}_{2}$ region $(-111 \mathrm{ppm})$. In contrast with silica gel and silicic acid (Temuujin et al 1997a,d), fumed silica almost contains no hydrated $\mathrm{Si}-\mathrm{O}$ units. Grinding of mixture introduces new ${ }^{27} \mathrm{Al}$ resonances at 62.4 and about $32.4 \mathrm{ppm}$. The latter has been ascribed to pentacoordinated $\mathrm{Al}$, or to distorted 4-coordinated $\mathrm{Al}$ associated with tricluster units which occur in mullite (Schmucker and Schneider 1996). The ${ }^{29} \mathrm{Si}$ spectrum of ground mixture shows the appearance of a new strong peak at about $-83 \mathrm{ppm}$ which reflects the presence of a significant proportion of the $\mathrm{Si}$ associated with aluminosilicate units (Temuujin et al 1997c). The ${ }^{27} \mathrm{Al}$ and ${ }^{29}$ Si MAS NMR spectra of the ground mixture suggest that grinding for $20 \mathrm{~h}$ produces homogeneous structures in which the $\mathrm{Si}$ and $\mathrm{Al}$ are intimately combined, consistent with the crystallization behaviour of this precursor.

These experiments suggest that fumed silica is more reactive to mechanochemical activation than silica gel, silicic acid and fused silica. Fumed silica, like fused silica, contains few hydroxyl groups, but the homogeneity of fumed silica + gibbsite mixtures as reflected by NMR measurements is much greater than fused silica + gibbsite mixtures (Temuujin et al 1997b). The present results suggest that the mechanochemical formation of amorphous aluminosilicate does not require the silica component to contain large concentration of hydroxyl groups. A more important factor may be the fineness and dispersion of the starting siliceous component (BET specific surface area of fumed silica is $200 \mathrm{~m}^{2} / \mathrm{g}$ and fused silica is $4.3 \mathrm{~m}^{2} / \mathrm{g}$ ), which can beneficially influence the preparation of aluminosilicate precursors by the mechanochemical method.

\section{Conclusions}

Mullite precursors were prepared by a mechanochemical method using gibbsite and fumed silica as starting materials. Judging by the homogeneity of the precursors, fumed silica is more reactive than silica gel, silicic acid and fused silica. These differences are attributed to the high degree of dispersion of the fumed silica (particle size less than several tens of nanometers), which is more completely adsorbed on the active sites of ground gibbsite, facilitating the formation of amorphous aluminosilicate.

\section{Acknowledgements}

The authors wish to thank A Shimai, Tokyo Institute of Technology, for performing FTIR measurements. One of the authors (JT) would like to thank UNESCO/MONBUSHO for the award of a research fellowship.

\section{References}

Liao J and Senna M 1993 Solid State Ionics 66313

Okada K and Otsuka N 1986 J. Am. Ceram. Soc. 69652

Schneider H, Okada K and Pask J 1994 Mullite and mullite ceramics (Chichester: Wiley) p. 105

Schmucker M and Schneider H 1996 Ber. Bunsenges Phys. Chem. 1001550

Temuujin J, Okada K and MacKenzie K 1997a J. Mater. Res. (in press)

Temuujin J, Okada K and MacKenzie K 1997b J. Eur. Ceram. Soc. (submitted)

Temuujin J, Okada K and MacKenzie K 1997c Ceram. Int. (in press)

Temuujin J, Okada K and MacKenzie K 1997d Mater. Lett. (submitted) 